\section{A tragic fire in Kensington, London}

The catastrophic conflagration that started at around $1 \mathrm{am}$ on Wednesday 14 June, ${ }^{1}$ apparently because of a refrigerator catching fire on the 4th floor of the 24-story building, Grenfell Tower, resulted in a very heavy loss of life, perhaps over a hundred people. The fire rapidly spread upwards, igniting most of the rest of the building, due to inflammable panels having been fitted to the exterior walls. Tower blocks are generally designed in such a way to ensure that fire starting in such a way - due to some defective electrical appliance, for exampleremains confined, perhaps to a single room or, at worst, to a single apartment (for example, each individual apartment has a fireproof door in the main entrance). Were this not so, presumably no one would wish to live or work in such block and they would never be occupied. In case of fire, residents in the rest of the building are typically advised to remain in their apartments, because it is highly likely that the fire can be extinguished, if necessary by the emergency services, before it is able to spread. Only in the case of an extraordinary event, such as a fuel-laden aeroplane colliding with the side of a skyscraper, as happened on 11 September 2001 at the World Trade Center in New York City, is the entire building destroyed. The Grenfell Tower fire is the worst tower block fire ever to happen in the UK.

Grenfell Tower was built in 1974 and is owned by the local authority - the Council of the Royal Borough of Kensington and Chelsea (RBKC). Its management had been outsourced to an organization called Kensington and Chelsea Tenant Management Organization (KCTMO), which collected rent from the tenants and was responsible for repairs. A refurbishment programme costing 8.6 million GBP had been completed in 2016. A major part of the refurbishment was the installation of external cladding, mainly for cosmetic purposes, but also to improve thermal insulation. The cladding was partly made of an organic polymer - variously stated to be polyethylene, polyester and polystyrene - and hence was inflammable, vitiating the principle of fire compartmentalization.

Residents had complained about many aspects of the building during the preceding years. These complaints were mostly channelled through the Grenfell Action Group. Electrical power surges were known to occur, perhaps due to faulty wiring engendering short circuits, constituting an obvious fire hazard. Natural gas was piped throughout the entire building, and following the refurbishment the main pipes rose through the sole stairwell, in the middle of the building, and were not specially fireproofed. It is not clear whether there was a central fire alarm system and whether it was working.

During the coming weeks and months, painstaking forensic work will doubtless uncover many details and perhaps provide more definitive knowledge regarding the origin of the fire and its extraordinarily rapid spreading, which was the most prominent feature. The point here is to call attention to some systemic features typical of present-day Britain that seem to have played an important rôle in engendering this catastrophe. It may be that these features will be beyond the remit of any enquiry.

With the enormous proliferation of building, fire and health \& safety regulations it might come as surprise that anything even remotely approaching this catastrophe could possibly happen. Yet, it has long been pointed out that such an environment can actually increase danger. The maxim "The way to be safe, is never to be secure" dates from the 17 th century. ${ }^{2}$ Several decades ago, the first-ever fire in the building, several hundred years old, housing Oxford University's Department of Geology was startedpresumably inadvertently-by building contractors installing a fire escape required by then newly introduced legislation. "Safety" regulations and insurance are pillars of the modern concept of security. Drafting and enforcing regulations has become a major industry in itself, employing large numbers of people as inspectors and members of bodies ("quangos") charged with overseeing the regulations and related activities. Insurance likewise has proliferated, becoming a very large industry. The fatal flaw in this concept is that individual responsibility is diminished. There seems to be no doubt that one acts more carefully when the consequences of carelessness are not covered by insurance. This seems to be a basic part of human psychology and is not even particularly subtle. ${ }^{4}$ Ewald's history of, especially, occupational accident insurance in France and how it led to the modern welfare state [3] does not address this issue, even within the narrowly circumscribed domain of occupational accidents. There is a characteristic difference between the approaches of

\footnotetext{
1 Information about the events has been gleaned from the national press-including the Daily Mail, Daily Telegraph, Financial Times and Guardian. Much of the information reported is not entirely self-consistent, nevertheless a plausible picture emerges. A full enquiry will, of course, be undertaken but it may be many months before investigations are complete and its findings are published.

2 Quoted in [1].

3 A more recent case concerning the installation of a lift in the Regent House of the University of Cambridge is instructive because it has been extensively documented [2].

4 The evolution away from the juridical concept of responsibility towards the actuarial concept of risk is described in Ewald's monumental work [3].
} 
France and England. In France, thinkers like Ewald tried to get to the bottom of the matter with the help of profound philosophical reflexion, but nevertheless seem to have missed what might be considered to be the most profound point of all, namely the diminution of the inner sense of personal responsibility by any kind of insurance; a fortiori, when social insurance reaches its apotheosis in the welfare state this diminution may become so pervasive it is not even noticed any longer. The point here is not that we should simply turn the clock back to the state of affairs that existed before the introduction of the modern welfare state; rather, had the emphasis remained on personal responsibility, advances in knowledge (reinforced by the availability of universal education), which in turn led to many other advances such as in medicine, could have made the path of individual and social development very different and avoided the general weakening of motivation that universal welfare seems to engender. ${ }^{5}$

Twentieth century England has not had its equivalents of Ewald (or Michel Foucault); a distinctively English view of the état providence can be found in some remarks made during the second reading debate about the NHS Bill on 30 April 1946: "the kind of society which the Minister [Aneurin Bevan, chief promoter of the Bill] is apparently envisaging ... is a society in which everybody pays to the State what he must, and takes from the State what he can. That is not the kind of society which will be very attractive to the people of this country" (Richard Law); and "[the present Government is] gradually killing the finest characteristics of our people - the spirit of enterprise and individual attainment. It appears to be a case of 'What can I get, what can I take and what can I procure for myself?' and not 'What can I give, how can I help, how can I serve?' ... this Bill saps the very foundations on which our national character has been built. It is yet another link in the chain which is binding us all to the machine of State ... It is depriving the individual of yet more of his long-fought-for freedom" (Viscountess Davidson). It is not possible to compare with what would have happened had the NHS not been created, and while there is much to be said for it as an efficient way of delivering healthcare to the population, one can also see how the traits identified by Law and Davidson have become endemic.
A striking feature of Britain's economy ${ }^{\mathbf{6}}$ nowadays is the tendency to outsource service activities. It seems to be considered an advantage (to the organization with ultimate responsibility, OUR) of this system that it circumscribes complaints and criticisms, shielding the person or organization with ultimate responsibility from the unpleasantness of having to deal with them. This "advantage"- which amounts to throwing away much valuable feedback - is balanced or indeed outweighed by the disadvantage to the recipients of the service, because their complaints are less likely to be dealt with. The OUR has a reputation to maintain, whereas the serviceproviding organization (SPO) is in a situation of conflict of interest: presumably it would like to provide a satisfactory service to the ultimate recipients of the service, but its standing with respect to the OUR is more likely to depend on its ability to provide the service at minimal cost. Where the service is of critical importance, such as cleaning in hospitals, the effect of outsourcing has been studied, and the finding is that the outsourced service is inferior to the in-house one [5]. ${ }^{7}$ The pressure on costs results in many services being only provided on a nominal basis. Economies are made with the staff, both by minimizing their numbers and by recruiting those of inferior abilities, who do not have to be paid as much. Complaints and criticisms are, therefore, increasingly likely to be dealt with tardily, or not at all, and when replies are received they may be unintelligible, because the staff are incapable of writing an intelligible paragraph or even a sentence. Overall, it appears that every effort is made to deflect and neutralize criticism. These features are all likely to characterize the KCTMO, which seems to have regarded the tenants in its care as nuisances to be contained rather than providing valuable feedback, saving it from having to employ inspectors to constantly observe the state of the buildings. In the case of Grenfell Tower, many improvements that could and should have been made were, evidently, not made.

Deflecting and neutralizing criticism is, increasingly, the apparent aim of government departments. Special units have been set up (the process might be called "internal outsourcing") to deal with "members of the public", defined as anyone not employed by the department, including professionals whose expertise

5 Perhaps the ultimate development of universal welfare is the "Qatar model": every citizen (there are about a quarter of a million) receives a share (about 10000 USD per annum) of the country's vast mineral oil wealth. No real work needs to be done in exchange; essential tasks are carried out by a vast number of foreigners, well over 1 million.

6 Many or most of the features can be found in many or most of the developed economies of the world. Presumably they are initially introduced because of some economic advantage and, hence, will in due course be followed elsewhere because of the continuous competitive pressure among countries to remain at the forefront.

7 This finding cuts away the ground that lies beneath the general justification of outsourcing, especially the "governmentowned, contractor-operated" (GOCO) model, namely that "private companies can deliver (public) services at lower cost than governments themselves, while maintaining or even increasing quality" [4]. 
may well exceed that of anyone in the department. An e-mail by my former colleague Frank Taylor to the "Ministerial Support Unit" of the Department for Transport perfectly captures the scene: ${ }^{8}$ “... I feel that some advice may help you provide a better and more appropriate response ... when a serious enquiry is made by a layperson then I advise that a serious and truthful reply be given ... What should be avoided at all costs is giving information that can easily be checked and found to be misleading. This makes the government and the civil service look foolish and incompetent. While I accept that a standard response may sometimes be satisfactory for lay inquiries I suggest that it is rather insulting, to put it mildly, to send the same response to professionals. Enquiries from anybody with obvious knowledge of the subject should be shown respect and answered individually and, of course, truthfully. If matters of security prevent a full answer from being given then so be it but if that is the case it should be clearly stated; to provide an answer known to be misleading should never be a condoned.

"I feel it necessary to point out that in my younger days I had considerable correspondence with the authorities ... and I almost invariably received a serious and considered reply. Often I did not fully agree with the reply but that was fine, the door was open for intelligent discussion ... Somehow this standard and quality of response seems to have been lost ...". The reasons for this loss appear to involve a mixture of intent and incompetence. The loss is likely to imply considerable economic loss (at least in the long term) and, probably more importantly, loss of goodwill.

Another now endemic feature of the modern British economy is the pervasiveness of the "making a fast buck" mentality. In the early years of the Industrial Revolution, fortunes were also rapidly made but generally on a foundation of laudable achievement and the innovations involved were genuinely popular. Over time the situation changed; the ADE-651 "bomb detector", widely deployed in Iraq, but which had a purely chrematistic function and no bomb detection capability at all (its supplier, James McCormick, was convicted of fraud in 2013), became more representative of the contemporary way of doing business. It was decided to refurbish Grenfell Tower and a significant part (about 30\%) was to be spent on fitting panels to the exterior façade (just over $3000 \mathrm{~m}^{2}$ ) with both a cosmetic and thermal insulating function (the option of spraying the building with thermally insulating material [6] was not, apparently, considered). Architects Studio E initially (2013) specified KMP Architectural Solutions" "Proteus" panels with a metallic core but Rydon, ${ }^{9}$ which oversaw the project, decided to commission Harley Facades $\operatorname{Ltd}^{\mathbf{1 0}}$ to supply and fit considerably cheaper Omni Exteriors" "Reynobond" panels - and not even the "FR" (fire-resistant) variety, but the even cheaper "PE" (polyethylene) type. Naturally enough, all these decisions were scrutinized by various panels, boards and councils, who evidently approved them. Corruption in the building industry is so endemic that it is the object of surveys and reports $[7,8]$. Seeing it condoned by the Council of RBKC is more reprehensible - the fact that corruption also seems to be endemic in UK local government [9] makes it no less so.

Local and central authorities alike appear to have hoped that free-market competition to provide services would provide a remedy against corruption. One might be able to make a theoretical case for the validity of this hope, but in practice it has not worked. A good illustration is the sad evolution of the privatized rail industry in the UK. The two great trunk routes are the "East Coast" and "West Coast" main lines running from London to Scotland. The West Coast operating franchise was given to Virgin Trains in 1997, which has operated it ever since, despite a poor record of uncomfortable and late trains. The East Coast has had a more chequered commercial history. It was operated by Sea Containers from 1996 until 2007, when it was taken over by National Express, which lasted only two years before operations were passed to Directly Operated Railways (DOR), part of the Department for Transport. The service provided by DOR was perfectly satisfactory, but in 2015 the franchise was given to

\footnotetext{
8 E-mail dated 16 August 2012.

9 It is possibly significant that in July 2013, a few months before the work on Granville Tower had begun, Rydon was awarded a contract to perform repair work on houses belonging to Sutton (in south London) Council, but in December 2014 the contract was prematurely terminated because of substandard performance.

${ }^{10}$ Harley Facades was called Harley Curtain Wall when commissioned to supply and fit the panels but went into administration in the same year, apparently because of almost 0.5 million GBP claimed by a previous client for disputed work and 2.5 million GBP claimed by HMRC. The managing director, Ray Bailey, was, however, allowed to buy the old company (for less than 2.5 thousand GBP), which then resumed trading under the new name. After the fire he commented that "we are not aware of any link between the fire and the exterior cladding to the tower". ${ }^{11}$

${ }^{11}$ Before condemning this statement as technically ignorant, or disingenuous, or both, one should reflect on the influence exerted by insurance companies. Many insurance contracts forbid any admission of liability by the insured party prior to a definitive assessment. As already pointed out, insurance promotes carelessness by transforming what would be an inadmissible action if personal responsibility were to be borne into one with a quantifiable risk, against which an insurance policy can be taken out.
} 
Virgin Trains, ${ }^{12}$ despite their reputation for unreliability. Therefore, there is no more competition on the London to Scotland route!

In fact, this hope was evidently stillborn because the privatization of utilities was accompanied by the creation of regulatory offices (Ofcom, Ofwat, ORR etc.). This simply pushes the problem to another level; the regulators have revealed themselves to be scarcely less corruptible than the companies that they are supposed to regulate. Quis custodet ipsos custodes? A regulator of regulators?

The combination of cupidity and venality that characterizes a modern economy is going to be very hard to eliminate. ${ }^{13}$ In the aftermath of the British Airways IT crisis on 27 May 2017, a journalist commented that "too many major corporations seem these days to be run for the benefit of a small clique of senior executives, with customers taken for granted and scant attention paid to the long-term needs of the business" [11]. Even the recent terrorist attacks in the UK seem to belong to the nadir of fortunes. Clear guidance on how to deal with the modern terrorist movement was provided some time ago [12], and although government and military figures have been alerted to the new concept, there is no evidence that any attention has been paid to it; conventional methods continue to be used.

It may be that cybernetic insight will provide the answer. Any complex system is characterized by basins of attraction with barriers between them, and after a time the system will inevitably get stuck in one of those basins [13]. Clearly this has happened in the UK and we have the misfortune that the basin is an unattractive, undesirable one. Only by administering a shock to the system can it be forced out of the basin into another one. The UK has suffered a number of major shocks over the last 12 months - the referendum result in favour of Brexit, terrorist attacks, the cyber attack on the NHS, the BA IT failure, the recent general election and now the Grenfell Tower conflagration. Let us hope that these shocks will suffice to move the nation into a new basin. It can scarcely be doubted that there are enough honest, active, intelligent and motivated citizens to take the initiative in forging a new path, once the stultifying environment of the present basin is left behind.

Doubtless the enquiry into Grenfell Tower will seek to not only to determine the technical causes of the fire but also find out who was accountable for deficiencies and apportion blame. That may come as a relief to some, but let us remember some words written by Erich Kästner: "An allem Unfug, der passiert, sind nicht etwa nur die schuld, die ihn tun, sondern auch die, die ihn nicht verhindern" [14]. There must be many who sat silently on committees while dubious measures were passed. Such actions, doubtless happening every day, all around the country, in both the public and private spheres, constitute a perversion of the privileges of membership of bodies charged with making decisions, or even merely giving advice. It would be better to resign than continue such abuse. Inasmuch as in some respects the whole nation constitutes a giant committee, we all share some blame for allowing wrongness to be promulgated.

J.J. RAMSDEN

\section{References}

1. J.J. Ramsden, Defining security. In: Complexity and Security (eds J.J. Ramsden and P.J. Kervalishvili), pp. 9-11. Amsterdam: IOS Press (2008).

2. A.W.F. Edwards, Epistles to the Oxonians on the construction of a lift into the Regent House Combination Room of the University of Cambridge. Oxford Magazine (Eighth Week, Michaelmas Term, 2009) 15-16; (Second Week, Hilary Term, 2010) 9-10; (Eighth Week, Hilary Term, 2010) 13-14; Noughth Week, Trinity Term, 2010) 12; (Fifth Week, Trinity Term, 2010) 20-21.

3. F. Ewald, L'Etat-Providence. Paris: Grasset (1986).

4. J.J. Ramsden, Outsourcing public services. Nanotechnol. Perceptions 12 (2016) 147-152.

5. D.M. Zuberi and M.B. Ptashnick, The deleterious consequences of privatization and outsourcing for hospital support work: The experiences of contracted-out hospital cleaners and dietary aids in Vancouver, Canada. Social Sci. Med. 72 (2011) 907-911.

6. F.S. Stepka, C.H. Liebert and S. Stecura, Summary of NASA Research on Thermal-Barrier Coatings (NASA TM X73581). SAE Trans. 86 (1977) 1487-1499.

7. Corruption in the UK Construction Industry. Ascot, Berks: The Chartered Institute of Building (CIOB) (2013).

8. Managing Bribery and Corruption Risks in the Construction and Infrastructure Industry. Ernst \& Young (2012).

9. Corruption in UK Local Government. Transparency International (2013).

10. Terror and the Postcolonial (eds E. Boehmer and S. Morton). Chichester: Wiley (2010).

11. J. Warner, Penny-pinching BA is digging its own grave. Daily Telegraph (2 June 2017).

12. S. Galam, The sociophysics of terrorism: a passive supporter percolation effect. In: Complexity and Security (eds J.J. Ramsden and P.J. Kervalishvili), pp. 13-37. Amsterdam: IOS Press (2008).

13. W.R. Ashby, The mechanism of habituation. In: Proc. Symp. on the Mechanization of Thought Processes, vol. 1, pp. 95-113.

14. E. Kästner, Der fliegende Klassenzimmer, ch. 7. Zürich: Atrium Verlag (1935).

\footnotetext{
${ }^{12}$ The franchisee is actually Virgin Trains East Coast, nominally a separate company.

${ }^{13}$ It is no less prevalent in Africa as in Europe (e.g., [10]).
} 